\title{
Adverse Cardiovascular Effects of Nitrous Oxide: It is not all about Hyperhomocysteinaemia
}

Ata Mahmoodpoor ${ }^{1}$, Samad EJ Golzari ${ }^{2^{*}}$

1. Department of Anesthesiology, Tabriz University of Medical Sciences, Tabriz, Iran

2. Medical Education Research Center, Tabriz University of Medical Sciences, Tabriz, Iran

Once admired for its supposed safety, nitrous oxide is presently blamed to increase adverse cardiovascular effects through augmenting plasma homocysteine concentrations $(1,2)$. Hemodynamic alterations following the administration of nitrous oxide are extremely complicated and sometimes contradictory. Enhanced venous return, arterial pressure, pulmonary and systemic vascular resistance, cardiac output, pupillary dilation and diaphoresis occur under nitrous oxide administration consistent with sympathomimetic properties of nitrous oxide (3). Conversely, reductions in arterial pressure are also probable, especially in patients with coronary artery disease. Nitrous oxide can also depress myocardial contractility due to decreased availability of $\mathrm{Ca} 2+$ for contractile activation; yet, myocardial relaxation kinetics remains intact (4). In the presence of a volatile anesthetic, nitrous oxide decreases $\mathrm{MVO} 2$ (Myocardial oxygen consumption) and myocardial $\mathrm{O} 2$ extraction which may exacerbate myocardial ischemia during concomitant reductions in arterial pressure in patients with coronary artery disease. Consequently, it could be conjectured that probable adverse cardiovascular effects following nitrous oxide administration are variable and consequent of a multi-variable phenomenon rather than a single variable such as increased levels of homocysteine. Studied purely focusing on the effects of nitrous oxide are difficult to conduct due to the numerous confounding factors.

In a study by Myles et al., hyperhomocysteinemia has been introduced as the source of the adverse cardiovascular effects of nitrous oxide. However, in this study, increased inspired oxygen concentrations were used to overcome arterial desaturation (1). Given the fact that a constant volume and flow rates are used throughout the anesthesia in a particular patient, increasing the concentrations of oxygen would be associated with decreased delivered nitrous oxide and volatile anesthetic concentrations due the dilution effect. This would alter the total and instantaneous nitrous oxide and volatile anesthetic delivery to the patients affecting the

\section{Corresponding author:}

Samad EJ Golzari, MD

Medical Education Research Center, Tabriz University of Medical Sciences, Tabriz, Iran

E-mail: dr.golzari@hotmail.com Phone:+989141151894

Receive date: 2014-12-19| Accept date: 2014-12-25| Publish date: 2015-01-29

DOI: 10.7575/aiac.abcmed.15.03.02.01 
results of the study. In the meantime, another confounding factor is the "Carrier Gas Composition". Vaporizer output is influenced by the composition of the carrier gas, i.e. oxygen, nitrous oxide or air, which flows through the vaporizer (5). Nitrous oxide is more soluble than oxygen in the halogenated liquid within the vaporizer sump, changing the composition of carrier gas would be associated with different steady-state values altering the amount of the delivered volatile anesthetic (6). Increased or decreased amounts of the delivered volatile agents play a major role in the hemodynamic and cardiovascular events both intra- and post-operatively. Factors that contribute to the characteristic steady-state response resulting when various carrier gases are used include the viscosity and density of the carrier gas, the relative solubility of the carrier gas in the anesthetic liquid, the flowsplitting characteristics of the specific vaporizer, and the concentration control dial setting (6).

\section{References}

1. Myles P.S, Chan M TV, Forbes A, et al. The safety of addition of nitrous oxide to general anaesthesia in at-risk patients having major non-cardiac surgery (ENIGMA-II): a randomised, single-blind trial. doi:10.1016/S01406736(14)60893-X

2. Badner NH, Drader K, Freeman D, Spence JD. The use of intraoperative nitrous oxide leads to postoperative increases in plasma homocysteine. Anesth Analg 1998; 87: 711-13.

3. Messina AG, Yao F-S, Canning $H$, et al: The effect of nitrous oxide on left ventricular pump performance and contractility in patients with coronary artery disease: Effect of preoperative ejection fraction. Anesth Analg 1993; 77:954-962.

4. Carton EG, Wanek LA, Housmans PR: Effects of nitrous oxide on contractility, relaxation and the intracellular calcium transient of isolated mammalian ventricular myocardium. J Pharmacol Exp Ther 1991; 257:843-849.

5. Diaz PD: The influence of carrier gas on the output of automatic vaporizers. Br J Anaesth 1976; $48: 387$.

6. Gould DB, Lampert BA, MacKrell TN: Effect of nitrous oxide solubility on vaporizer aberrance. Anesth Analg 1982; 61:938. 